\title{
Persepsi Guru Penjas Terhadap Pembelajaran Daring di Tengah Pandemi Covid-19 Pada SMA Negeri Se-Kabupaten Jepara
}

\author{
M. Izzama Indra ${ }^{1}$, Pandu Kresnapati ${ }^{2}$, Fajar Ari Widiyatmoko ${ }^{3}$ \\ ${ }^{123}$ Universitas PGRI Semarang. Jl. Gajah Raya No.40, Semarang \\ Mizzamaindra08@gmail.com, pandukresnapati@upgris.ac.id, fajarariwidiyatmoko@upgris.ac.id
}

\begin{abstract}
The purpose of this research is to see the perceptions of physical education teachers towards courageous learning in the midst of the Covid-19 pandemic at Public High Schools in Jepara Regency. There are also benefits, namely as an evaluation material for the knowledge of Physical Education teachers in SMA Negeri Jepara Regency. This research is a quantitative study using descriptive methods (Descriptive Research). The data of this study were sourced from the results of a survey on filling out a questionnaire by 28 Physical Education teachers in SMA Negeri Jepara Regency, in this case the teacher became a research. The data collected individually is descriptive based so that it does not seek explanations, hypotheses, make predictions, or learn implications. The results of this study indicate that the perceptions of Physical Education teachers towards courageous learning in the midst of the Covid-19 pandemic at Public High Schools throughout Jepara Regency are in the "very unsupporting" category by $18 \%$ (5 teachers), the "unsupporting" category is $43 \%$ (12 teachers), the "supporting" category was $25 \%$ ( 7 teachers), the "very supportive" category was $14 \%$ (4 teachers). So it can be concluded that the perception of sports Physical Education teachers towards online learning in the midst of the Covid-19 pandemic at SMA Negeri Jepara Regency is in the "unsupported" category. Suggestions for other researchers would be better if you use open questionnaires or interviews, respondents are more directly and carefully monitored at the time of data collection, so that the resulting data is more valid and for further researchers to use further instruments in this study
\end{abstract}

Keywords: Physical education teacher responses, online learning, Covid-19

\begin{abstract}
Abstrak
Tujuan peneletian ini untuk mengetahui persepsi guru pendidikan jasmani terhadap pembelajaran daring di tengah pandemi covid-19 pada SMA Negeri Se-Kabupaten Jepara. Ada juga manfaatnya yaitu Sebagai bahan evaluasi terutama bagi pengetahuan para guru penjasorkes di SMA Negeri Se Kabupaten Jepara. Penelitian ini merupakan penelitian kuantitatif dengan menggunakan metode deskriptif (Descriptive Research). Data penelitian ini bersumber dari hasil survey pengisian angket oleh 28 guru penjas di SMA Negeri Se-Kabupaten Jepara, dalam hal ini guru tersebut menjadi responden penelitian. Data yang dikumpulkan semata-mata bersifat deskriptif sehingga tidak bermaksud mencari penjelasan, menguji hipotesis, membuat prediksi, maupun mempelajari implikasi. Hasil penelitian ini menunjukkan bahwa persepsi guru Pendidikan Jasmani olahraga terhadap pembelajaran daring di tengah pandemi covid-19 pada SMA Negeri Se-Kabupaten Jepara berada pada kategori "sangat tidak menunjang" sebesar 18\% (5 guru), kategori "tidak menunjang" sebesar 43\% (12 guru), kategori "menunjang" sebesar 25\% (7 guru), kategori "sangat menunjang" sebesar 14\% (4 guru). Sehingga dapat disimpulkan bahwa persepsi guru Pendidikan Jasmani olahraga terhadap pembelajaran daring di tengah pandemi covid-19 pada SMA Negeri Se-Kabupaten Jepara masuk dalam kategori "tidak menunjang". Saran bagi peneliti lain akan lebih baik jika menggunakan angket terbuka atau wawancara, responden lebih dipantau secara langsung dan cermat pada saat pengambilan data, sehingga data yang dihasilkan lebih valid dan bagi peneliti selanjutnya agar lebih menyempurnakan instrumen yang digunakan dalam penelitian ini.
\end{abstract}

Kata kunci: Tanggapan guru penjas, pembelajaran daring, Covid-19 


\section{PENDAHULUAN}

Mata pelajaran Pendidikan jasmani sering dijumpai sebagai mata pelajaran yang condong terhadap aspek psikomotor atau keterampilan gerak. Melalui keterampilan gerak itulah nantinya akan dapat mengajarkan atau menambah pengetahuan siswa yang masuk dalam aspek kognitif. Kemudian juga dari keterampilan gerak yang ajarkan siswa juga ditanamkan nilai-nilai sosial seperti disiplin, tanggung jawab, sportif, dan lain sebagainya yang masuk dalam aspek afektif. Pendidikan jasmani tidak akan mencapai tujuan tanpa adanya rencana yang matang dalam proses pembelajaranya.

Berdasarkan Surat Edaran Kemendikbud No. 4 Tahun 2020 Tentang Pelaksanaan Kebijakan Pedidikan dalam Masa Darurat Penyebaran Coronavirus Diseases (COVID-19) menyatakan bahwa proses belajar dilakukan melalui pembelajaran daring. Model pembelajaran tersebut dilaksankan untuk memberikan pembelajaran yang bermakna bagi siswa ditengah pandemi. Selain itu aktivitas dan tugas pembelajaran Belajar dari Rumah dapat bervariasi antarsiswa, sesuai minat dan kondisi masing-masing, termasuk mempertimbangkan kesenjangan akses/ fasilitas belajar di rumah.

Pembelajaran daring merupakan pembelajaran yang memanfaatkan teknologi multimedia, video, kelas virtual, teks online animasi, pesan suara, email, telepon konferensi, dan video steraming online. Pembelajaran dapat dilakukan secara masif dengan jumlah peserta yang tidak terbatas, bisa dilakukan secara gratis maupun berbayar (Bilfaqih \& Qomarudin, 2015). Menurut Harnani, (2020) tenaga pendidik dalam sistem pembelajaran daring harus memastikan kegiatan belajar mengajar tetap berjalan, meskipun siswa berada di rumah. Solusinya, guru dituntut dapat mendesain media pembelajaran sebagai inovasi dengan memanfaatkan media daring (online).Implikasi kebijakan Surat Edaran Kemendikbud No. 4 Tahun 2020 mengakibatkan perubahan yang luar biasa terhadap dunia pendidikan. Seluruh jenjan g pendidikan 'dipaksa' bertransformasi untuk beradaptasi secara drastis untuk melakukan pembelajaran dari rumah melalui media daring (Balitribune.co.id, 2020). Dalam pengimplementasian pembelajaran daring sebagai bentuk pembelajaran jarak jauh untuk siswa, wajib mengedepankan dua prinsip, yaitu: (1) Tidak membahayakan, dimana pembelajaran yang dilaksanakan secara daring tidak menciptakan lebih banyak stres dan kecemasan bagi siswa dan keluarganya, (2) Realistis, pembelajaran yang dilaksanakan guru secara dari memiliki ekspektasi yang realistis terhadap tujuan pembelajaran yang hendak dicapai (Kemendikbud, 2020).

Ketidaksiapan guru dan siswa terhadap pembelajaran daring juga menjadi masalah. Perpindahan sistem pembelajaran dari konvensional (tatap muka) menjadi daring akan terasa sulit apabila tidak dipersiapkan secara matang. Berdasarkan hasil survey Federasi Serikat Guru Indonesia (FSGI) dan Komisi Perlindungan Anak Indonesia (KPAI) yang dilansir dari Beritasatu.com (2020) kepada 602 guru (responden) di 14 provinsi ditemukan fakta hanya $8 \%$ guru yang mengerti memakai gawai untuk belajar daring. Sementara ada $82,4 \%$ yang minim memakai gawai untuk belajar daring, dan 9,6\% sama sekali tidak pernah memakai gawai untuk belajar daring. Kenyataan inilah yang membuat Pembelajaran Jarak Jauh menjadi model pembelajaran yang tidak menarik bagi siswa. Mayoritas guru dalam PJJ hanya 
memahami penggunaan media teknologi digital dalam pembelajaran sebatas menggunakan WhatsApp, Line, Instagram, dan Facebook," kata Satriwan dalam paparan hasil survei "Persepsi dan Evaluasi Guru terhadap Pelaksanaan Pembelajaran Jarak Jauh (PJJ)” secara daring di Jakarta, Selasa (28/4/2020).

Dengan demikian guru dituntut mampu merancang dan mendesain pembelajaran daring yang ringan dan efektif, dengan memanfaatkan perangkat atau media daring yang tepat dan sesuai dengan materi yang diajarkan. Keberhasilan guru dalam melakukan pembelajaran daring pada situasi pandemi Covid-19 ini adalah kemampuan guru dalam berinovasi merancang, dan meramu materi, metode pembelajaran, dan aplikasi apa yang sesuai dengan materi dan metode. Pengimplementasian pembelajaran daring sebagai sebuah "new normal" di sekolah hendaknya guru merancang pembelajaran daring yang dapat memfasilitasi siswa untuk mengkonstruksi pengetahuannya dan pemecahan masalah sehingga terbentuk pembelajaran yang bermakna. Keberhasilan pelaksanaan pembelajaran daring tidak terlepas dari beberapa hal berikut, diantaranya (1) keterampilan penggunaan TIK, (2) ketersedian Teknologi, (3) Mandirian belajar, (4) kedisiplinan, (5) tanggung jawab.

Kreatifitas merupakan kunci sukses dari seorang guru untuk dapat memotivasi siswanya tetap semangat dalam belajar secara daring (online) dan tidak menjadi beban psikis. Selain itu kesuksesan pembelajaran daring selama masa Covid-19 ini tergantung pada kedisiplinan semua pihak. Kerjasama yang baik antara guru, siswa, orang tua siswa dan pihak sekolah atau madrasah menjadi faktor penentu agar pembelajaran daring lebih efektif. Maka berdasarkan uraian di atas, dengan mengacu pada metode pembelajaran secara daring, jarak jauh atau belajar dari rumah dengan menggunakan jaringan internet. Peneliti sangat ingin mengetahui "Persepsi Guru Pendidikan Jasmani Olahraga dan Kesehatan Terhadap Pembelajaran Daring di Tengah Pandemi Covid-19 Pada SMA Negeri Se-Kabupaten Jepara”.

\section{METODE}

Desain Penelitian

Penelitian ini adalah penelitian deskriptif kuantitatif. Menurut Suharsimi Arikunto (2006:139), penelitian deskriptif adalah penelitian yang hanya menggambarkan keadaan atau status fenomena. Penelitian deskriptif kuantitatif mempunyai tujuan untuk mendeskripsikan suatu fenomena, peristiwa, gejala, dan kejadian yang terjadi secara faktual, sistematis, serta akurat. Jenis penelitian ini menjelaskan suatu fenomena dengan menggunakan angka yang menggambarkan karakteristik subjek yang diteliti sebagaimana adanya. Penelitian ini mendeskripsikan data kuantitatif yang didapatkan berkaitan dengan keadaan subjek dari populasi. Metode yang digunakan dalam peneltian ini adalah metode survey dengan teknik pengumpulan data menggunakan angket. Peneliti akan menggunakan pendekatan kuantitatif dengan analisis data hasil penyebaran angket/kuesioner. Skor dari perolehan penyebaran angket 
kemudian diolah dan dianalisis dengan menggunakan statistik deskriptif yang dituangkan dalam bentuk pengkategorian dan presentase.

Populasi dan sampel

Dalam penelitian ini target populasinya adalah seluruh guru pendidikan jasmani di SMA Negeri Se-Kabupaten Jepara yang berjumlah 28 guru dari keseluruhan 9 SMA Negeri yang ada dan untuk uji coba instrumen sejumlah 33 guru pendidikan jasmani yang ada. Penelitian ini adalah penelitian populasi. Sampel yang diambil dalam penelitian ini adalah semua guru Pendidikan jasmani di SMA Negeri Se-Kabupaten Jepara dengan jumlah 28 guru penjas dengan metode survey dan teknik pengumpulan data menggunakan angket. Teknik dan instrument pengumpulan data ada beberapa teknik yang dapat digunakan. Berikut ini teknik yang digunakan peneliti dalam pengumpulan data: Kuesioner diberikan kepada guru penjas SMA Negeri Se-Kabupaten Jepara yang menjadi responden untuk mengetahui persepsi pembelajarn daring di tengah pandemic Covid-19. Adapun mekanismenya adalah sebagai berikut: 1. Peneliti mencari data guru pendidikan jasmani Olahraga dan Kesehatan di SMA Negeri Se-Kabupaten Jepara. 2. Peneliti menyebarkan angket kepada responden. 3. Selanjutnya peneliti mengumpulkan angket dan melakukan transkrip atas hasil pengisian angket. 4. Setelah memperoleh data penelitian peneliti menganalisis lebih lanjut.

Instrumen penelitian

Angket dalam penelitian ini adalah angket tertutup. Menurut Arikunto (2006:102-103), angket tertutup adalah angket yang disajikan dalam bentuk sedemikian rupa sehingga responden tinggal memberikan tanda check list $(\sqrt{ })$ pada kolom atau tempat yang sesuai, dengan angket langsung menggunakan skala bertingkat. Skala bertingkat dalam angket ini menggunakan modifikasi skala likert dengan 4 pilihan jawaban. Ada tiga langkah yang perlu diperhatikan, yaitu; 1) Mendefinisikan Konstruk ;2) Menyidik Faktor; 3) Menyusun Butir-butir pertanyaan. Langkah ketiga dalam Menyusun instrumen adalah menyusun butir pertanyaan berdasarkan faktor yang menyusun konstrak. Kemudian peneliti melakukan validasi angket dengan validator.

\section{F. Teknik Analisis Data}

Teknik analisis data dalam penelitian ini menggunakan teknik analisis data deskriptif kuantitatif. Statistik deskriptif digunakan untuk memberi gambaran tentang data yang diteliti, tanpa melakukan analisis dan membuat kesimpulan yang berlaku umum (Sugiyono, 2016). Menurut Sudijono (2009:121) rumus deskriptif. Untuk memperjelas proses analisis maka dilakukan pengkategorian. Pengkategorian tersebut menggunakan Mean dan Standar Deviasi. Menurut Azwar (2010:43) untuk menentukan kriteria skor dengan menggunakan Penilaian Acuan Norma (PAN) dalam skala pada tabel 1 sebagai berikut: 
Tabel 1. Norma Penilaian Persepsi Guru Pendidikan Jasmani terhadap Pembelajaran Daring pada SMA Negeri Se-Kabupaten Jepara.

\begin{tabular}{clc} 
No. & \multicolumn{1}{c}{ Interval } & Kategori \\
\hline 1 & $\mathrm{M}+1 \mathrm{SD}<\mathrm{X}$ & Sangat Menunjang \\
\hline 2 & $\mathrm{M}+0,5 \mathrm{SD}<\mathrm{X} \leq \mathrm{M}+1 \mathrm{SD}$ & Menunjang \\
\hline 3 & $\mathrm{M}-1 \mathrm{SD}<\mathrm{X} \leq \mathrm{M}+0,5 \mathrm{SD}$ & Tidak Menunjang \\
\hline 5 & $\mathrm{X} \leq \mathrm{M}-1 \mathrm{SD}$ & Sangat Tidak Menunjang \\
\hline
\end{tabular}

Sumber: Azwar (2010:43)

\section{HASIL DAN PEMBAHASAN}

1. Hasil analisis deskriptif kuantitatif pembelajaran daring

Hasil analisis data persepsi guru Pendidikan Jasmani olahraga terhadap pembelajaran daring di tengah pandemi covid-19 pada SMA Negeri Se-Kabupaten Jepara diperoleh nilai tertinggi (maksimum) sebesar 122,00, dan nilai terendah (minimum) 90,00. Untuk rerata (mean) diperoleh nilai sebesar 109,7500, standar deviasi (SD) 7,90511. Hasil selengkapnya dapat dilihat pada tabel 2 sebagai berikut:

Tabel 2. Hasil Analisis Data Persepsi Guru

\begin{tabular}{lcccccc}
\hline & \multicolumn{2}{c}{ Minimu } & Maximu & & \\
& $\mathrm{N}$ & $\mathrm{m}$ & $\mathrm{m}$ & Sum & Mean & Std. Deviation \\
\hline PERSEPSI & 28 & 90.00 & 122.00 & 3073.00 & 109.7500 & 7.90511 \\
\hline Valid N (listwise) & 28 & & & & & \\
\hline
\end{tabular}

Sumber: Data Primer yang di Olah, 2020

Apabila ditampilkan dalam bentuk distribusi frekuensi, maka data persepsi guru pendidikan jasmani olahraga terhadap pembelajaran daring di tengah pandemi Covid-19 pada SMA Negeri SeKabupaten Jepara disajikan pada tabel 3 sebagai berikut: 
Tabel 3. Distribusi Frekuensi Persepsi Guru Pendidikan Jasmani Olahraga Terhadap Pembelajaran Daring Di Tengah Pandemi Covid-19 Pada SMA Negeri Se-Kabupaten Jepara.

\begin{tabular}{ccccc} 
No. & \multicolumn{1}{c}{ Interval } & Kategori & $\mathrm{F}$ & $\%$ \\
\hline 1 & $117,655<\mathrm{X}$ & Sangat Menunjang & 4 & $14 \%$ \\
\hline 2 & $113,702<\mathrm{X} \leq 117,655$ & Menunjang & 7 & $25 \%$ \\
\hline 3 & $101,845<\mathrm{X} \leq 113,702$ & Tidak Menunjang & 12 & $43 \%$ \\
\hline 5 & $\mathrm{X} \leq 101,845$ & Sangat Tidak Menunjang & 5 & $18 \%$ \\
\hline \multicolumn{2}{c}{ JUMLAH } & 28 & $100 \%$ \\
\hline
\end{tabular}

Sumber: Data Primer yang diolah, 2020

Berdasarkan tabel 4.3 di atas menunjukkan bahwa persepsi guru Pendidikan Jasmani olahraga terhadap pembelajaran daring di tengah pandemi covid-19 pada SMA Negeri Se-Kabupaten Jepara berada pada kategori "sangat tidak menunjang" sebesar 18\% (5 guru), kategori "tidak menunjang" sebesar 43\% (12 guru), kategori "menunjang” sebesar 25\% (7 guru), kategori "sangat menunjang" sebesar 14\% (4 guru). Berdasarkan nilai rata-rata, yaitu 109,7500, persepsi guru Pendidikan Jasmani olahraga terhadap pembelajaran daring di tengah pandemi covid-19 pada SMA Negeri Se-Kabupaten Jepara masuk dalam kategori "tidak menunjang”.

Apabila ditampilkan dalam bentuk gambar, maka data Persepsi Guru Pendidikan Jasmani Olahraga Terhadap Pembelajaran Daring Di Tengah Pandemi Covid-19 Pada SMA Negeri SeKabupaten Jepara tampak pada gambar 1 sebagai berikut:

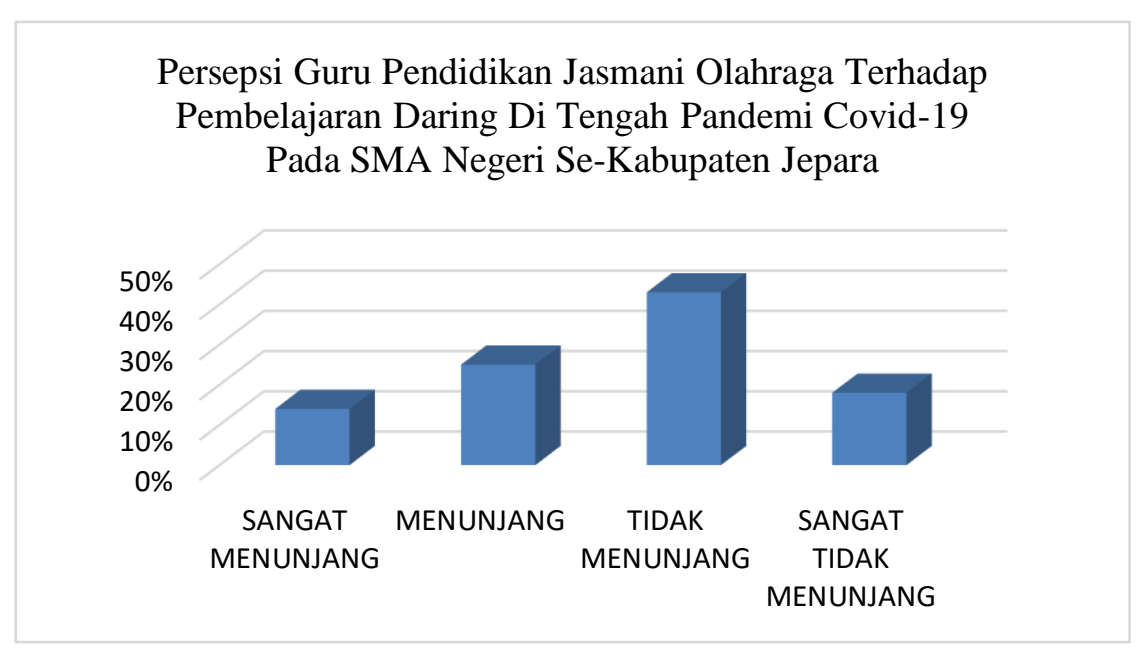

Gambar 1. Diagram Batang Persepsi Guru Pendidikan Jasmani Olahraga Terhadap Pembelajaran Daring Di Tengah Pandemi Covid-19 Pada SMA Negeri Se-Kabupaten Jepara 


\section{Pembahasan}

Penelitian ini bertujuan untuk mengetahui persepsi guru pendidikan jasmani olahraga terhadap pembelajaran daring di tengah pandemi Covid-19 pada SMA Negeri Se-Kabupaten Jepara berdasarkan faktor guru, siswa, sarpras, waktu, dan materi. Berdasarkan hasil analisis menunjukkan persepsi guru pendidikan jasmani olahraga terhadap pembelajaran daring di tengah pandemi covid-19 pada SMA Negeri Se-Kabupaten Jepara masuk dalam kategori "tidak menunjang". Secara lebih rinci, dijelaskan persepsi guru pendidikan jasmani olahraga terhadap pembelajaran daring di tengah pandemi covid-19 pada SMA Negeri Se-Kabupaten Jepara berdasarkan faktor guru, siswa, sarpras, waktu, dan materi sebagai berikut:

\section{Faktor Guru}

Berdasarkan hasil analisis menunjukkan bahwa persepsi guru pendidikan jasmani olahraga terhadap pembelajaran daring di tengah pandemi covid-19 pada SMA Negeri Se-Kabupaten Jepara berdasarkan faktor guru masuk dalam kategori tidak menunjang. Hasil tersebut menunjukkan bahwa faktor guru dalam ketrampilan penggunaan aplikasi media komunikasi, kesiapan penggunaan aplikasi media pembelajaran, ketrampilan pembuatan model dan setrategi pembelajaran daring, serta pelaksanaan mengajar dengan metode daring belum maksimal.

\section{Faktor Siswa}

Berdasarkan hasil analisis menunjukkan bahwa persepsi guru pendidikan jasmani olahraga terhadap pembelajaran daring di tengah pandemi covid-19 pada SMA Negeri Se-Kabupaten Jepara berdasarkan faktor siswa masuk dalam kategori tidak menunjang. Hasil tersebut menunjukkan bahwa ketrampilan penggunaan aplikasi media komunikasi dan kedisiplinan siswa mengikuti proses pembelajaran daring belum optimal.

\section{Faktor Sarpras}

Berdasarkan hasil analisis menunjukkan bahwa persepsi guru pendidikan jasmani olahraga terhadap pembelajaran daring di tengah pandemi covid-19 pada SMA Negeri Se-Kabupaten Jepara berdasarkan faktor sarpras masuk dalam kategori tidak menunjang. Ketersediaan sarana dan prasarana yang berupa gawai (android), laptop, akses internet, dan aplikasi pembelajaran daring seharusnya menjadi hal yang tidak asing lagi bagi siswa SMA Negeri Se-Kabupaten Jepara. Namun pada kenyataanya masih ada beberapa siswa yang kesulitan dan menemui hambatan untuk mendapatkan akses tersebut. Apabila ditampilkan dalam bentuk diagram, maka persepsi guru pendidikan jasmaniolahraga terhadap pembelajaran daring di tengah pandemi covid-19 pada SMA Negeri SeKabupaten Jepara

\section{Faktor Waktu}

Berdasarkan hasil analisis menunjukkan bahwa persepsi guru pendidikan jasmani olahraga terhadap pembelajaran daring di tengah pandemi covid-19 pada SMA Negeri Se-Kabupaten Jepara 
berdasarkan faktor waktu masuk dalam kategori tidak menunjang. Guru telah menyampaikan materi sesuai dengan Rencana Pelaksanaan Pembelajaran (RPP) yang telah di buat sebelumnya. Selain itu guru juga telah memberikan tugas sesuai dengan materi yang disampaikan dan memberikan kesempatan untuk diskusi dengan siswa dalam materi praktek maupun teori. Namun pada kenyataanya ada beberapa siswa yang kurang bisa mengikuti jadwal sekolah yang di buat secara daring. Baik karena unsur kesengajaan maupun adanya hambatan siswa untuk mengikuti kelas daring.

\section{Faktor Materi}

Berdasarkan hasil analisis menunjukkan bahwa persepsi guru pendidikan jasmani olahraga terhadap pembelajaran daring di tengah pandemi covid-19 pada SMA Negeri Se-Kabupaten Jepara berdasarkan faktor materi masuk dalam kategori menunjang. Peran guru terhadap suksesnya pembelajaran daring sangat besar. Untuk mengetahui materi yang diajarkan pada siswa guru tidak dapat melakukan penilaian ataupun pengamatan sendiri. Guru Penjas di SMA Negeri Se-Kabupaten Jepara mempunyai satu group tersendiri untuk saling bertukar pikiran dan kendala yang di hadapi selama metode daring digunakan di tengah Pandemi Covid-19.

\section{KESIMPULAN}

Berdasarkan hasil analisis data, deskripsi hasil penelitian, dan pembahasan, dapat diambil kesimpulan bahwa persepsi guru Pendidikan Jasmani olahraga terhadap pembelajaran daring di tengah pandemi covid-19 pada SMA Negeri Se-Kabupaten Jepara berada pada kategori "sangat tidak menunjang" sebesar 18\% (5 guru), kategori "tidak menunjang” sebesar 43\% (12 guru), kategori "menunjang" sebesar 25\% (7 guru), kategori "sangat menunjang” sebesar 14\% (4 guru). Sehingga dapat disimpulkan bahwa persepsi guru Pendidikan Jasmani olahraga terhadap pembelajaran daring di tengah pandemi covid-19 pada SMA Negeri Se-Kabupaten Jepara masuk dalam kategori “tidak menunjang”. 
Persepsi Guru Penjas Terhadap Pembelajaran Daring di Tengah Pandemi

Covid-19 Pada SMA Negeri Se-Kabupaten Jepara

M. Izzama Indra, Pandu Kresnapati, Fajar Ari Widiyatmoko

\section{DAFTAR PUSTAKA}

Arikunto, S. (2006). Prosedur Penelitian Suatu Pendekatan Praktek. Jakarta: Rineka Cipta.

Azwar, S. (2010). Sikap Manusia Teori dan Pengukurannya. Yogyakarta: Pustaka Pelajar.

Bilfaqih, Y \& Qomarudin, M. N. (2015). Esensi Pengembangan Pembalajaran Daring.

Harnani. (2020). Efektivitas pembelajaran daring di masa pandemi covid-19. Bdkjakarta.Kemenag.Go.Id.

Kemendikbud. (2016). Kamus Besar Bahasa Indonesia.

Sudijono, A. (2009). Pengantar evaluasi pendidikan. Jakarta: Raja Grafindo.

Sugiyono. (2016). Metode Penelitian Kuantitatif, Kualitatif, Dan R\&D. Bandung: PT. Alfabet.

Surat Edaran Menteri Pendidikan dan Kebudayaan Republik Indonesia No. 4 Tahun 2020 Tentang Pelaksanaan Kebijakan Pedidikan dalam Masa Darurat Penyebaran Coronavirus Diseases (COVID-19). 300.

Undang-Undang Republik Indonesia Nomor 20 Tahun 2003 Tentang Sistem Pendidikan Nasional. (2003). Undang-Undang Republik Indonesia Nomor 20 Tahun 2003 Tentang Sistem Pendidikan Nasional. https://doi.org/10.16309/j.cnki.issn.1007-1776.2003.03.004. 